\title{
Gender Differences in FOBT Use: Evidence from a Large German Survey
}

Authors

Affiliation

\author{
M. Sieverding, U. Matterne, L. Ciccarello
}

Ruprecht-Karls-Universität Heidelberg, Germany

\section{Bibliography}

DOI $10.1055 / s-2007-963489$

Z Gastroenterol 2008; 46:

S47-S51 @ Georg Thieme

Verlag KG Stuttgart . New York. ISSN 0044-2771

\section{Correspondence \\ Monika Sieverding}

Department of Psychology,

Ruprecht-Karls-Universität

Heidelberg

Hauptstr. $47-51$

69117 Heidelberg

Germany

Tel.: ++ 49/62 21/547372

Fax: $++49 / 6221 / 547325$

monika.sieverding@

psychologie.uni-heidelberg.de

\section{Abstract $\nabla$}

We examined prevalence and correlates of fecal occult blood testing (FOBT) uptake in a sample of men and women aged 50 to 70 years without a personal history of cancer $(n=15810)$. The data was collected in 2004 through the Health Care Access Panel (HCAP), a nationally generalizable survey of German households. A pronounced gender difference in FOBT use emerged. Women reported regular use more often, while men reported irregular use with a higher frequency. Nearly every third men (29.6\%), compared to $17.5 \%$ of the women had never made use of FOBT. The influence of socioeconomic factors on FOBT uptake was negligible. Family history of cancer was significantly associated with FOBT but the effect was very small. Use of medical checkups and physician recommendation were the most important predictors of FOBT use in men and women. Gender differences in use of medical checkups and physician recommendation to undergo an examination for the early detection of cancer partly mediated the gender differences in FOBT use.

\section{Introduction}

$\nabla$

Over the last years, gender differences in colorectal cancer test use have attracted the attention of several researchers, stemming from the fact that men in general are more reluctant to seek medical care and usually make less use of the health care system for preventive reasons [1 - 3]. Several European studies reported a higher utilization of fecal occult blood tests (FOBT) in women than men [4-9], a phenomenon which was also discussed on the 2007 European conference on colon cancer prevention in Brussels (see for example the contributions by Malila, Segnan or Steele in this supplement).
In Germany, fecal occult blood testing with Hemoccult was introduced as the standard procedure for the early detection of colorectal cancer in 1977. It was offered annually to individuals from age 50 and paid by mandatory public health insurance. All measures for the early detection of cancer take place by opportunistic screening rather than the eligible population receiving an invitation letter. Since its introduction women have displayed higher levels of FOBT use than men, especially in the younger age groups $[4,10]$. In 2002 , eligibility to undergo a screening colonoscopy every ten years was added to the standard catalog of measures of secondary prevention. Since then individuals from age 55 can choose whether they want to have a colonoscopy every ten years or a FOBT every two years. Between ages 50-54 the FOBT is still offered annually. Analyses show a marked gender difference in use of screening colonoscopies especially in lower age groups as well (see G. Brenner, this supplement [11, 12]).

Since only little is known about gender differences regarding correlates of colorectal cancer (CRC) test use $[2,13]$ a main goal of our study was to assess gender differences in prevalence of FOBT use as well as in the correlates of that use. So far, most studies assessed FOBT use dichotomously for a specific time frame (usually the last year or the last two years). Similarly, the prevalence estimates of CRC test use from official statistics in Germany only give an indication of use within the last year [14]. Assessing it thus yields no information as to how regular FOBT use occurs. As regularity of FOBT use is a prerequisite for the effectiveness (the sensitivity is low if the test is performed only once) we assessed use of FOBT by three possible options (never, irregularly, regularly every $1-2$ years). We also included sociodemographic measures (age, marital status, income or education) which had been identified as correlates of CRC test use in various studies [15-18]. Several variables can serve as "cues to action" to (colorectal) 
cancer screening as previous research has demonstrated, for instance family history of cancer $[2,17]$, number of physician visits $[13,16]$, physician recommendation [17] and use of general medical checkups [19]. These variables were also assessed.

\section{Method}

$\nabla$

\section{Participants and Procedure}

The data for the study were collected through the Health Care Access Panel (HCAP) [20]. It uses a sampling method specifically designed to arrive at samples representing the characteristics of the population at large. The HCAP of the year 2004 contained 71446 persons, aged $20-70$ years. The sample for the present study was constituted by selecting all persons aged 50 - 70 from the HCAP and originally consisted of 17146 adults. 1336 persons with a personal history of cancer were excluded from the study. The final sample for the present study comprised 15810 adults (7735 men and 8075 women) aged $50-$ 70 , the mean age was 58 years (men: $M=58.1, S D=5.5$, women: $M=58.3, S D=5.7$ ). All of the participants were health insured. Data collection took place between August and October 2004 by mailed questionnaires.

\section{Measures}

$\nabla$

\section{Sociodemographic variables}

Sociodemographic variables included age in years, marital status, family size, education ( $9^{\text {th }}$ grade or under, $10^{\text {th }}$ grade, High school certificate, College graduate), monthly family income and health insurance status (public versus private).

\section{Fecal occult blood test (FOBT) use}

Participants were asked whether and how regularly they had undergone a test of fecal occult blood in the past with the possible answers "never", "irregularly", “regularly every 1 - 2 years".

Cues to action variables: Family history of cancer, physician recommendation and use of medical checkups

Family history of cancer was assessed by asking the participants whether they had knowledge of (any) cancer amongst their grand parents, parents or siblings ("no", "yes, one person", "yes, two or more persons"). Physician recommendation was assessed by asking participants whether a physician had recommended they undergo a test for the early detection of cancer $(1=$ yes, $0=$ no/I don't know). Use of general medical checkups was measured by asking participants to indicate on a four-point scale ("never", "irregularly", "every two years" or "annually") whether and how regularly they had attended a free medical checkup as provided by the German health care system starting at age 35 .

The development of the questionnaire involved piloting and pretesting the items in independent samples to ensure its clarity and comprehension.

\section{Statistical analyses and data transformation}

Final data were weighed to be nationally representative for all analyses with the exception of the sample description. Statistical analyses were carried out using SPSS for Windows (Version 14). Gender differences in prevalence rates of FOBT use were examined by $\chi^{2}$-tests.
Correlates of regularity of FOBT use were analysed by linear multiple hierarchical regressions, entering sociodemographic variables (including sex) in the first step, and the cues to action variables in the second step.

\section{Results}

$\nabla$

\section{Gender differences in sociodemographic variables}

Women lived alone more often, held fewer college degrees, reported lower income and held a private health insurance less often than men. These results mirror the socioeconomic differences between men and women in the general German population [21].

\section{Gender differences in cues to action variables}

More women (48\%) than men (39\%) reported to have had one or more family member(s) with cancer. A higher percentage of women (66\%) than men (54\%) reported ever having received a recommendation to undergo an investigation for the early detection of cancer from a physician. Women also attended medical checkups more regularly than men. Every fourth man (26\%) but only $14 \%$ of the women indicated never having attended a medical checkup. The characteristics of the study sample are displayed in Table 1.

\section{Prevalence of FOBT use}

A pronounced gender difference emerged in the pattern of FOBT use. As can be seen from 0 Fig. 1 women had used FOBT on a regular basis more often than men $\left(\chi^{2}=466.3, \mathrm{df}=2, \mathrm{p}<0.001\right.$, Cramer's $V=0.18$ ). While $63 \%$ of the women reported FOBT use every $1-2$ years, the respective number for men was much smaller (46\%); $30 \%$ of the men reported never having used a FOBT.

\section{Multivariate linear hierarchical regression models pre- dicting regularity of FOBT use}

Sociodemographic variables were entered in the first step, to be followed by family history of cancer, physician recommendation and use of medical checkups in the second step ( Table 2). All sociodemographic variables including age and sex explained only a small amount of variance in FOBT use $\left(5 \% \hat{=} \mathrm{R}^{2}=.05\right)$, most of which was attributable to sex. Sociodemographic variables appear to play only a negligible role in predicting FOBT use in our sample. Considering only first step variables, education for example was no significant predictor and the other sociodemographic variables although being significant added lit-

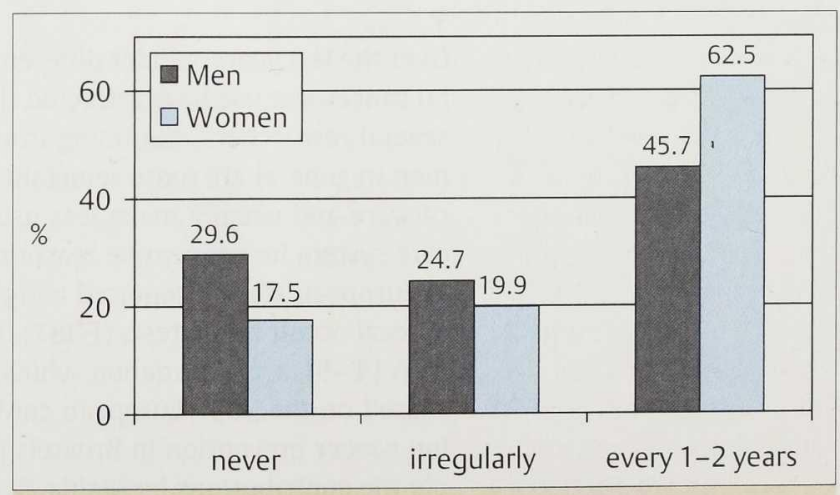

Fig. 1 Past FOBT use as a function of $\operatorname{sex}(n=15810)$. 
Table 1 Study population summary $(n=15810$ [persons without a personal history of cancer])

\begin{tabular}{|c|c|c|c|}
\hline & men & women & \\
\hline & $(n=7735)$ & $(n=8075)$ & \\
\hline & $\%$ & $\%$ & $\begin{array}{l}P \\
\text { value }\end{array}$ \\
\hline age (years) & & & $<0.01$ \\
\hline $50-54$ & 31.5 & 34.2 & \\
\hline $55-59$ & 26.7 & 25.1 & \\
\hline $60-64$ & 25.1 & 24.1 & \\
\hline $65-70$ & 16.7 & 16.6 & \\
\hline marital status & & & $<0.001$ \\
\hline married & 83.0 & 69.2 & \\
\hline $\begin{array}{l}\text { single/separated/ } \\
\text { divorced/widowed }\end{array}$ & 17.0 & 30.8 & \\
\hline family size & & & $<0.001$ \\
\hline 1 & 11.2 & 20.8 & \\
\hline 2 & 51.7 & 53.8 & \\
\hline 3 & 20.2 & 16.6 & \\
\hline 4 & 12.3 & 6.6 & \\
\hline$\geq 5$ & 4.6 & 2.2 & \\
\hline education & & & $<0.001$ \\
\hline $9^{\text {th }}$ grade or under & 48.7 & 49.6 & \\
\hline $10^{\text {th }}$ grade & 24.3 & 33.3 & \\
\hline high school graduation & 7.9 & 6.4 & \\
\hline college graduation & 19.1 & 10.7 & \\
\hline family income per month & & & $<0.001$ \\
\hline$<1750 €$ & 33.1 & 45.1 & 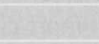 \\
\hline $1750-2749 €$ & 35.4 & 31.4 & \\
\hline$\geq 2750 €$ & 31.5 & 23.5 & \\
\hline health insurance & & & $<0.001$ \\
\hline public & 86.0 & 92.5 & \\
\hline private & 14.0 & 7.5 & \\
\hline family cancer history & & & $<0.001$ \\
\hline no & 60.9 & 52.1 & \\
\hline yes: 1 person & 29.9 & 32.6 & \\
\hline yes: $\geq 2$ persons & 9.2 & 15.3 & \\
\hline $\begin{array}{l}\text { physician recommendation } \\
\text { (cancer screening) }\end{array}$ & & & $<0.001$ \\
\hline no & 46.4 & 33.9 & \\
\hline yes & 53.6 & 66.1 & \\
\hline use of medical checkup & & & $<0.001$ \\
\hline never & 25.6 & 14.2 & \\
\hline irregularly & 28.2 & 24.0 & \\
\hline every two years & 21.0 & 22.3 & \\
\hline
\end{tabular}

tle to the prediction of FOBT use as indicated by their small betas. When second step variables were added individual betas of most sociodemographic variables decreased even further and each sociodemographic variable contributed only a minimal amount of unique variance (all less than $0.2 \%$ ) to the prediction of FOBT ( Table 2 ).

Adding the cues to action variables physician recommendation, use of medical checkups and family history of cancer in the second step significantly improved the predictive power of the model $\left(\Delta R^{2}=0.35\right)$. Use of medical checkups and physician recommendation emerged as the strongest predictors. A small effect was observed for family history of cancer. Use of medical checkups contributed the largest amount of unique variance to the prediction of FOBT (23\%).

As can be seen in Table 2 the impact of the variable "sex" was notably reduced in the second step when cues to action
Table 2 Results from linear hierarchical regression predicting FOBT utilization

\begin{tabular}{|c|c|c|c|c|}
\hline \multirow[b]{2}{*}{ predictor } & \multicolumn{2}{|l|}{ step 1} & \multicolumn{2}{|l|}{ step 2} \\
\hline & & unique & & unique \\
\hline & beta & variance & beta & variance \\
\hline \multicolumn{5}{|l|}{$\begin{array}{l}\text { sociodemographic } \\
\text { variables }\end{array}$} \\
\hline $\operatorname{sex}^{2}$ & $0.18^{3}$ & $3.0 \%$ & $0.06^{3}$ & $0.3 \%$ \\
\hline age $^{4}$ & $0.07^{3}$ & $0.4 \%$ & $0.03^{3}$ & $<0.1 \%$ \\
\hline marital status ${ }^{5}$ & $0.08^{3}$ & $0.4 \%$ & $0.03^{3}$ & $<0.1 \%$ \\
\hline family size ${ }^{6}$ & $-0.09^{3}$ & $0.5 \%$ & $-0.04^{3}$ & $<0.1 \%$ \\
\hline education 7 & $0.01^{14}$ & $<0.1 \%$ & $0.02^{8}$ & $<0.1 \%$ \\
\hline income $^{9}$ & $0.08^{3}$ & $0.4 \%$ & $0.03^{3}$ & $<0.1 \%$ \\
\hline health insurance $e^{10}$ & $-0.07^{14}$ & $<0.1 \%$ & $0.02^{8}$ & $<0.1 \%$ \\
\hline \multicolumn{5}{|l|}{$\begin{array}{l}\text { cues to action } \\
\text { variables }\end{array}$} \\
\hline $\begin{array}{l}\text { use of medical } \\
\text { checkup }^{11}\end{array}$ & & & $0.52^{3}$ & $3.0 \%$ \\
\hline $\begin{array}{l}\text { physician recom- } \\
\text { mendation }^{12}\end{array}$ & & & $0.19^{3}$ & $23.0 \%$ \\
\hline $\begin{array}{l}\text { family history of } \\
\text { cancer }{ }^{13}\end{array}$ & & & $0.04^{3}$ & $0.1 \%$ \\
\hline$\Delta R^{2}$ & $0.05^{3}$ & & $0.35^{3}$ & \\
\hline$R_{\text {cum(adjusted) }}^{2}$ & 0.05 & & 0.40 & \\
\hline 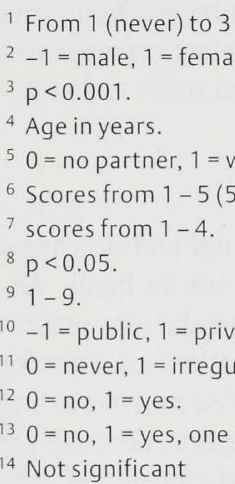 & $\begin{array}{l}\text { e. } \\
\text { rly, } 2=\text { eve } \\
2=y\end{array}$ & $\begin{array}{l}2 \text { years, } 3= \\
\text { more than } 0\end{array}$ & $\begin{array}{l}\text { nually. } \\
\text { eperson. }\end{array}$ & \\
\hline
\end{tabular}

variables were added. Its unique variance decreased from $3 \%$ (Step 1) to $0.3 \%$ (Step 2) indicating cues to action variables particularly use of medical checkups - to partly mediate the gender difference in FOBT use.

\section{Discussion}

$\nabla$

We found a striking gender difference in FOBT use. A larger percentage of men reported never having used the test. The percentage of irregular users was also much higher among men. These results support findings from previous studies in which FOBT use tended to be generally lower in men as compared to women (see introduction) $[13,16]$. The size of this effect was even larger in our study which may be attributed to the way we assessed FOBT use. Unlike most previous studies which assessed FOBT use within the last one or two years, we asked participants to report regularity of FOBT use. In Germany the FOBT is often combined with a medical checkup; the fact that men compared to women make use of these checkups less often and less regularly may explain their lower use of FOBT. This backs the internationally observed trend of men to generally make less use of the health care system $[1,22]$, particularly for preventive reasons. 
It appears that men have more difficulty engaging in a preventive behavior which has to take place regularly (i.e. annually) than women.

Men also reported family members with cancer significantly less often than women, a finding which was also reported by Wardle et al. [2] (UK) and McQueen et al. [13] (US). Compared to women, men are perhaps not as well informed about illness among their relatives (e.g. grandparents). Alternatively, they may tend to forget cancer in their family more readily. Glanz and colleagues [23] asked relatives of patients with colon cancer and found males more likely to be unaware of colorectal cancer in siblings or parents than females.

Although a significant association between family history of cancer and FOBT use was noted, the effect was not strong. We did not assess family history of colorectal but any cancer; if we had, a stronger association might have been found. We found attendance of regular medical checkups a very high-ranking correlate of FOBT use. Individuals having undergone medical checkups regularly reported more regular use of FOBT. We also found an association between a physician recommendation and FOBT use. The important role of medical checkups and physician recommendation in colorectal cancer test use has been demonstrated in a number of studies [16, 19, 24, 25]. It appears that individuals being in regular contact with the medical system, for example by regularly seeing their doctor can be reached more easily to be reminded to undergo CRC early detection measures especially when screening is opportunistic and there is no invitation system.

\section{Study limitations and strengths}

The present study used a cross-sectional design and no causal interpretations of the observed associations can be made. Another limitation refers to the assessment of the data by self-report. When comparing self-report with medical record audit for several cancer tests Hall et al. [26] demonstrated over-reporting of previous cancer test participation by self-report. Although we cannot rule out over-reporting in our study, the observed gender differences in the patterns of self-reported CRC test use parallel the findings from official statistics for the use of FOBT [4, 14].

Positive aspects of the study pertain to the large sample, which was drawn using a method to arrive at samples representing the general population. Hence, the results are highly generalizable. Furthermore, potential confounding effects of health insurance and other monetary inequalities play no role in Germany since health insurance is mandatory and no additional payment is necessary for CRC tests. Another strength pertains to the fact that we assessed the regularity of FOBT use rather than (one-off) FOBT use within a particular time interval to reflect adherence to the recommended interval.

\section{Conclusions}

Nearly half of the men in our sample had not received (or could not remember) a physician recommendation to undergo an early examination of cancer and every fourth man (26\%) had never undergone a medical checkup, which highlights the need to intensify systematic counseling about preventive behavior and (colorectal) cancer testing especially for men. The evident gender difference in (recalled) family history of cancer as found in this and other studies should receive more attention in future research and also be acknowledged more in general and physician's practice.

\section{Note}

This study was funded by a grant from "Deutsche Krebshilfe" (German Cancer Aid).

\section{References}

1 Courtenay WH. Constructions of masculinity and their influence on men's well-being: A theory of gender and health. Social Science \& Medicine 2000; 50: 1385-1401

2 Wardle J, Miles A, Atkin W. Gender differences in utilization of colorectal cancer screening. Journal of Medical Screening 2005; 12: 20-27

3 O'Brien R, Hunt $K$, Hart G. 'It's caveman stuff, but that is to a certain extent how guys still operate': men's accounts of masculinity and help seeking. Social Science \& Medicine 2005; 61: 503-516

4 Gnauck R. Screening for colon cancer in Germany. Tumori 1995; 81: 30-37

5 Hardcastle JD, Chamberlain JO, Robinson MH et al. Randomised controlled trial of fecal-occult-blood screening for colorectal cancer. Lancet 1996; 348: 1472-1477

6 Brevinge H, Lindholm E, Buntzen S et al. Screening for colorectal neoplasia with fecal occult blood testing compared with flexible sigmoidoscopy directly in a $55-56$ years' old population. International Journal of Colorectal Disease 1997; 12: 291-295

7 U. K. Colorectal Cancer Screening Pilot Group. Results of the first round of a demonstration pilot of screening for colorectal cancer in the United Kingdom. BMJ 2004; 329: 133

8 Faivre J, Dancourt V, Lejeune C et al. Reduction in colorectal cancer mortality by fecal occult blood screening in a French controlled study. Gastroenterology 2004; 126: 1674-1680

9 Segnan N, Senore C, Andreoni B et al. Randomized Trial of Different Screening Strategies for Colorectal Cancer: Patient Response and Detection Rates. J Natl Cancer Inst 2005; 97: 347-357

10 Becker N. Epidemiological aspects of cancer screening in Germany. Journal of Cancer Research \& Clinical Oncology 2003; 129: 691-702

11 Knöpnadel J, Altenhofen L, Lichtner F et al. Früherkennung des Darmkrebses und möglicher Vorstufen - Wissenschaftliche Reihe des Zentralinstituts, Band 59 (Early detection of colorectal cancer and possible pre-stages). Köln: Deutscher Ärzteverlag, 2005

12 Sieg A, Theilmeier A. Ergebnisse der Vorsorge-Koloskopie 2005 - Internet-basierte Dokumentation (Results of coloscopy screening in 2005 an Internet-based documentation). Deutsche Medizinische Wochenschrift 2006; 131: 379-383

13 McQueen A, Vernon SW, Meissner HI et al. Are there gender differences in colorectal cancer test use prevalence and correlates? Cancer Epidemiol Biomarkers Prev 2006; 15: 782-791

14 Altenhofen L. Hochrechnung zur Akzeptanz von Gesundheitsuntersuchungen und Krebsfrüherkennungsuntersuchungen bei gesetzlich Versicherten (Extrapolation data regarding acceptance of health check-ups and early detection cancer screenings for the population of people covered by public health insurance). Zentralinstitut für die kassenärztliche Versorgung in der Bundesrepublik Deutschland, 2005

15 Cokkinides VE, Chao A, Smith RA et al. Correlates of underutilization of colorectal cancer screening among U. S. adults, age 50 years and older. Preventive Medicine 2003; 36: 85-91

16 Seeff LC, Nadel MR, Klabunde CN et al. Patterns and predictors of colorectal cancer test use in the adult U.S. population. Cancer 2004; 100 : 2093-2103

17 Slattery ML, Kinney AY, Levin TR. Factors associated with colorectal cancer screening in a population-based study: the impact of gender, health care source, and time. Preventive Medicine 2004; 38: 276-283

18 Wardle J, McCaffery K, Nadel M et al. Socioeconomic differences in cancer screening participation: comparing cognitive and psychosocial explanations. Social Science \& Medicine 2004; 59: 249-261

19 Zapka JG, Puleo E, Vickers-Lahti M et al. Healthcare system factors and colorectal cancer screening. American Journal of Preventive Medicine 2002; 23: 28-35

20 Potthoff $P$, Heinemann $L A$, Güther B. A household panel as a tool for cost-effective health-related population surveys: validity of the 
"Healthcare Access Panel". German Medical Science 2004; 2: Doc5. http://www.egms.de/en/gms/2004-2/000015.shtml

21 Federal Statistical Office. Statistical Yearbook for the Federal Republic of Germany. Wiesbaden: Statistisches Bundesamt (Federal Statistical Office), 2005

22 Addis ME, MahalikJR. Men, masculinity, and the contexts of help seeking. American Psychologist 2003; 58: 5-14

23 Glanz K, Grove J, Le Marchand L et al. Underreporting of Family History of Colon Cancer: Correlates and Implications. Cancer Epidemiol Biomarkers Prev 1999; 8: 635-639
24 Gilbert A, Kanarek N. Colorectal cancer screening: Physician recommendation is influential advice to Marylanders. Preventive Medicine 2005; 41: 367-379

25 Lemon S, Zapka J, Puleo E et al. Colorectal cancer screening participation: Comparisons with mammography and prostate-specific antigen screening. American Journal of Public Health 2001; 91: 1264-1272

26 Hall HI, Van Den Eeden SK, Tolsma DD et al. Testing for prostate and colorectal cancer: comparison of self-report and medical record audit. Preventive Medicine 2004; 39: 27-35 